\title{
O ZONEAMENTO BIOCLIMÁTICO DA NBR 15220-3 E AS CONSTRUÇÕES RURAIS PARA BOVINOCULTURA DE LEITE EM ANHUMAS-SP
}

Juliana Domingues Scatolon', Maria Alessandra Bacaro Boscoli², Tadeu Alcides Marques ${ }^{1}$, Brenna Rocha Rotondo ${ }^{3}$

\footnotetext{
${ }^{1}$ Universidade do Oeste Paulista - UNOESTE, Programa de Mestrado em Meio Ambiente e Desenvolvimento Regional, Presidente Prudente, SP.

${ }^{2}$ Universidade do Oeste Paulista - UNOESTE, curso de Arquitetura e Urbanismo, Presidente Prudente, SP.

${ }^{3}$ Universidade do Oeste Paulista - UNOESTE, curso de Zootecnia, Presidente Prudente, SP. E-mail:

julianascatolon@gmail.com
}

\section{RESUMO}

O desempenho produtivo e o bem-estar do rebanho leiteiro é influenciado pelas construções rurais destinadas ao manejo em climas tropicais, pois as altas temperaturas e variações de umidade do ar alteram as respostas fisiológicas causando estresse térmico. A vaca leiteira é um animal homeotérmico com temperatura corporal e respostas fisiológicas ao estresse térmico parecidas com a dos humanos, por tanto, este trabalho apresenta as técnicas construtivas existente nas edificações rurais destinada a ordenha bovina como formas de aberturas e materiais construtivos associando a Norma Brasileira de Regulamentação, NBR 15220 de Desempenho térmico de edificações, Parte3: Zoneamento Bioclimático e diretrizes construtivas para habitações unifamiliares de interesse social.

Palavras Chave: Bovinocultura de leite, Conforto térmico, Bem-estar animal, NBR 15 220, Arquitetura Bioclimática.

\section{THE BIOCLIMATIC ZONING OF NBR 15220-3 AND THE RURAL CONSTRUCTIONS FOR DAIRY CATTLE OF ANHUMAS-SP}

\begin{abstract}
The productive performance and welfare of the dairy cattle is influenced by rural buildings destined to management in tropical climate, where high temperatures and moisture the air alter the physiological responses causing thermal stress. The dairy cow is a homeothermic animal with body temperature and physiological responses cause stress similar humans. This work presents the constructive techniques existing in the rural buildings destined to dairy cattle as forms of openings and constructive materials associating the Brazilian Standard Of Regulation, NBR 15220 of Thermal performance of buildings, Part 3: Bioclimatic Zoning and constructive guidelines for detached houses of social interest.
\end{abstract}

KeyWords: Dairy cattle, Thermal comfort, Animal welfare, NBR 15220, Bioclimatic architecture.

\section{INTRODUÇÃO}

Diversos fatores tem impacto negativo ou positivo sobre a produção animal, principalmente na produção leiteira, entre eles estão o manejo inadequado, baixo poder aquisitivo dos produtores em investimentos de infraestrutura e melhoramento genético, salubridade do ambiente onde os animais são ordenhados, a influência das altas/baixas temperaturas e as variações de umidade do ar. Quando as construções destinadas ao manejo animal são projetas ou executadas de forma inadequada, podem comprometer as funções 
fisiológicas por estresse térmico pelo excesso de frio ou calor podendo levar o animal a óbito além de prejudicar o desempenho produtivo.(TAKAHASHI et.al, 2009; BORGES et. al., 2003)

O clima tropical é predominante no Brasil e caracterizado por uma estação seca que se estende entre maio e setembro e uma estação chuvosa entre outubro e abril, as temperaturas são elevadas durante $\mathrm{o}$ ano variando entre 10 e $45^{\circ} \mathrm{C}$ e os dias tem variações de 20 e $25^{\circ} \mathrm{C}$ (VIANA, 2013)

De acordo com Baêta e Silva (2012, p.18) o bovino é um animal homeotermo, ou seja, ele "[...] mantém a temperatura do núcleo corporal dentro de limites relativamente estreitos, mesmo que a temperatura ambiental flutue e que a sua atividade varie intensamente[...] Se o mecanismo hemocinético não funcionar, o ambiente interno se iguala ao externo e o animal morre. "

Os animais homeotermos possuem temperatura corporal que varia em diferentes lugares internamente e em tempos diferentes, porém a temperatura do núcleo do corpo é mentida sempre a um mesmo nível que independe da variação da temperatura externa. A temperatura do núcleo corporal é resultado das funções fisiológicas que cada espécie utiliza para se manter, porém, humanos, equinos e bovinos possuem temperatura de núcleo semelhantes entorno de 37 e $38,5^{\circ} \mathrm{C}$. (ESMAY, 1969; MOUNT, 1979; BAÊTA e SILVA, 2012)

O trabalho teve como objetivo estudar as técnicas construtivas utilizadas por dois produtores rurais da Bacia Leiteira de Anhumas, identificando os materiais construtivos das edificações e estabelecendo paralelos com a Norma Brasileira NBR 15220 de Desempenho térmico de edificações para humanos levando em consideração a proximidade de temperatura corporal necessária para o bem-estar animal e humano.

\section{METODOLOGIA}

A pesquisa se utilizou de uma abordagem qualitativa, por meio de visitas as propriedades e de levantamentos bibliográficos que segundo Teixeira (2000, p.137), tem como objetivo a correlação entre os dados e a teoria, entre contexto e a ação e a interpretação dos fenômenos por meio das suas descrições.

Para a compreensão da relação entre as construções rurais e o que se é esperado para bem-estar animal foi utilizada a bibliografia de Baêta e Souza (2012), "Ambiência em Edificações Rurais", e a NBR 15220 de Desempenho Térmico de Edificações Parte 3: Zoneamento Bioclimático Brasileiro e Diretrizes Construtivas para Habitações Unifamiliares de Interesse Social, que estabelece os parâmetros construtivos para humanos.

Para a pesquisa foram escolhidas duas propriedades com características construtivas diferentes, a Propriedade A de alvenaria com telha de zinco galvanizado e a propriedade B de madeira e cobertura de telha de fibrocimento (Brasilit $\left.{ }^{\circledast}\right)$. Para a identificação da Zona bioclimática em que se encontra o município de Anhumas - SP foi utilizado o ZBBR 1.1 (Zoneamento Bioclimático Brasileiro de acordo com a NBR 15220-3)

Após estabelecer todas as relações entre técnicas construtivas existentes in loco e o que a NBR 15220-3 apresenta como ideal para conforto térmico e bem-estar, foi possível compreender a problemática existente nas construções rurais destinadas a bovinocultura de leite.

\section{O BEM ESTAR E A PRODUÇÃO ANIMAL - AS CINCO LIBERDADES}

A agropecuária vem apresentando considerável preocupação com um processo de produção ético e que respeite as boas práticas, considerando o bem-estar animal e dos trabalhadores envolvidos, a segurança alimentar mundial e a preservação do meio ambiente. (CAMPOS, 2009) 
No ano de 1992 a Farm Animal Welfare Council (FAWC) apresentou um plano para o desenvolvimento de programas de criação animal intitulado "cinco liberdades", este plano aborda a capacitação dos trabalhadores envolvidos na produção, registro da propriedade produtora por georreferenciamento e certificação de qualidade emitido pelos órgãos de fiscalização de produção de cada país. As cinco liberdades exigidas pela FAWC (1992) são,

- Liberdade de medo e angustia: O manejo dos animais deve ocorrer de acordo com o conhecimento básico das raças produzidas, respeitando as suas particularidades e evitando estresse quando transferidos, carregados ou descarregados.

- Liberdade de dor, sofrimento e doenças: A produção deve ser acompanhada da assistência de um bom plano veterinário, a fim de prevenir e proteger os animais de doenças e quaisquer outros acontecimentos que provoquem dor. Em caso de necessidade os animais devem receber atendimento profissional o mais rápido possível.

- Liberdade de fome e sede: A alimentação deve ser satisfatória, apropriada para cada espécie e segura. $O$ espaço oferecido nos comedouros e bebedouros deve ser adequado e suficiente, pois é fundamental para que não haja competição entre os animais. $O$ acesso à água potável e limpa deve ser facilitado e constante.

- Liberdade de desconforto: O ambiente do animal deve ser concebido respeitando a particularidade das espécies e as necessidades dos animais, fornecendo proteção e prevenção de desconfortos físicos e térmicos.

- Liberdade para expressar seu comportamento normal: Conhecimento fisiológicos e etológicos devem ser empregados para concepção das instalações e equipamentos.

Outros fatores englobam os planejamentos do programa de bem-estar animal como a contingencia em caso de danos estruturais nas construções, a utilização de geradores para falta de energia ou até mesmo falta de água, por tanto todo sistema produtivo deve ser dotado de opções alternativas para mitigar acontecimentos que privem os animais do direito as cinco liberdades. (BAÊTA e SOUZA, 2012)

O programa de bem-estar deve abordar as questões ambientais de higiene para garantir a integridade dos animais e dos trabalhadores, portanto, é necessário que exista um sistema de monitoramento de umidade, temperatura, ventilação, radiação, barulho e luminosidade. 0 monitoramento da temperatura, umidade e ventilação deve levar em consideração a espécie produzida, o peso dos animais, idade e estado fisiológico. (BAÊTA e SOUZA, 2012)

A FAWC (1992) estabelece ainda como parte do programa de bem-estar na produção a quantidade de animais por área, ou seja, a unidade deve atender adequadamente o porte dos animais permitindo que estes expressem seu comportamento normal, sendo necessário a existência de um programa de biossegurança com ações de vacina e manejo sanitário que evitem a entrada e saída de patógenos da instalação rural.

\section{AS CONSTRUÇÕES RURAIS DA BACIA LEITEIRA DE ANHUMAS - SÃO PAULO}

A Bacia leiteira de Anhumas está localizada na bacia hidrográfica do rio Santo Anastácio, este nasce entre os municípios de Anhumas e Regente Feijó e percorre 20,5 km de canal principal no sentido SE-W. (DIBIESO, 2012)

Entre as unidades produtoras de leite de Anhumas foram escolhidas duas para o desenvolvimento deste trabalho, por terem características construtivas diferentes.

A propriedade $A$, apresenta como sistema construtivo paredes de alvenaria na sala de ordenha e cobertura de estrutura metálica com telhas de zinco galvanizado. Todas as fachadas 
possuem aberturas em fita na parte superior próximas a cobertura funcionando como efeito chaminé. A fachada Norte apresenta três janelas e a leste apenas uma. O piso é de concreto e sem revestimento para que os animais não escorreguem, a ordenha ocorre com 8 animais de cada vez com sistema de fosso em espinha de peixe. O ponto mais alto da cobertura possui 3 metros de pé direito.

Figura 01. Abertura das fachadas, implantação da instalação rural (N-S) e sala de ordenha
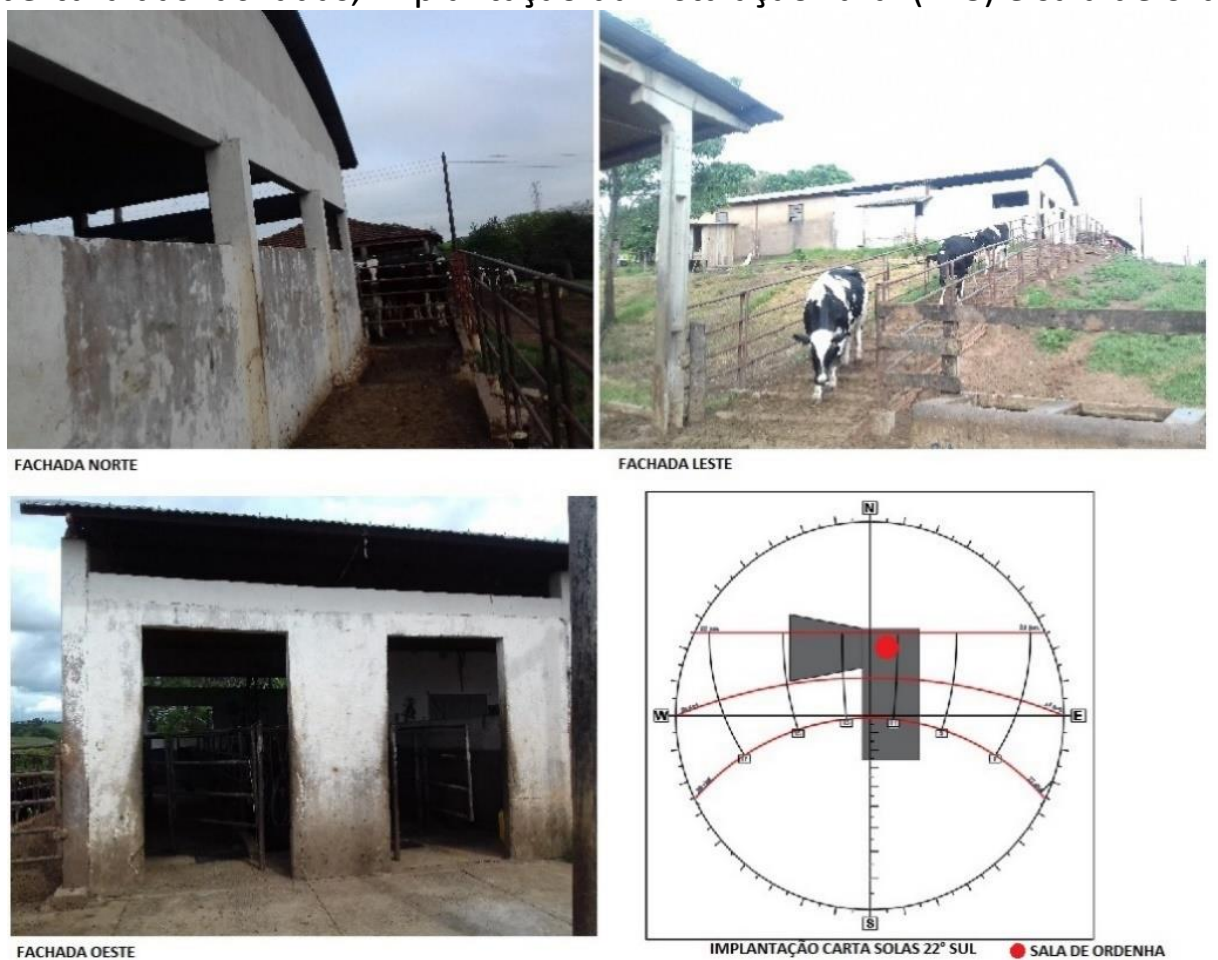

Fonte: Dados organizados pela autora, 2017

Na propriedade B o sistema construtivo é o primário para manejo bovino, característico das antigas "mangueiras bovinas" construído com tabuas de madeira, telhas de fibrocimento (Brasilit ${ }^{\circledast}$ ), piso de concreto sem revestimento e pé direito baixo entorno de 2,60 metros. 
Figura 02. Condições físicas, implantação da instalação rural (N-S) e sala de ordenha

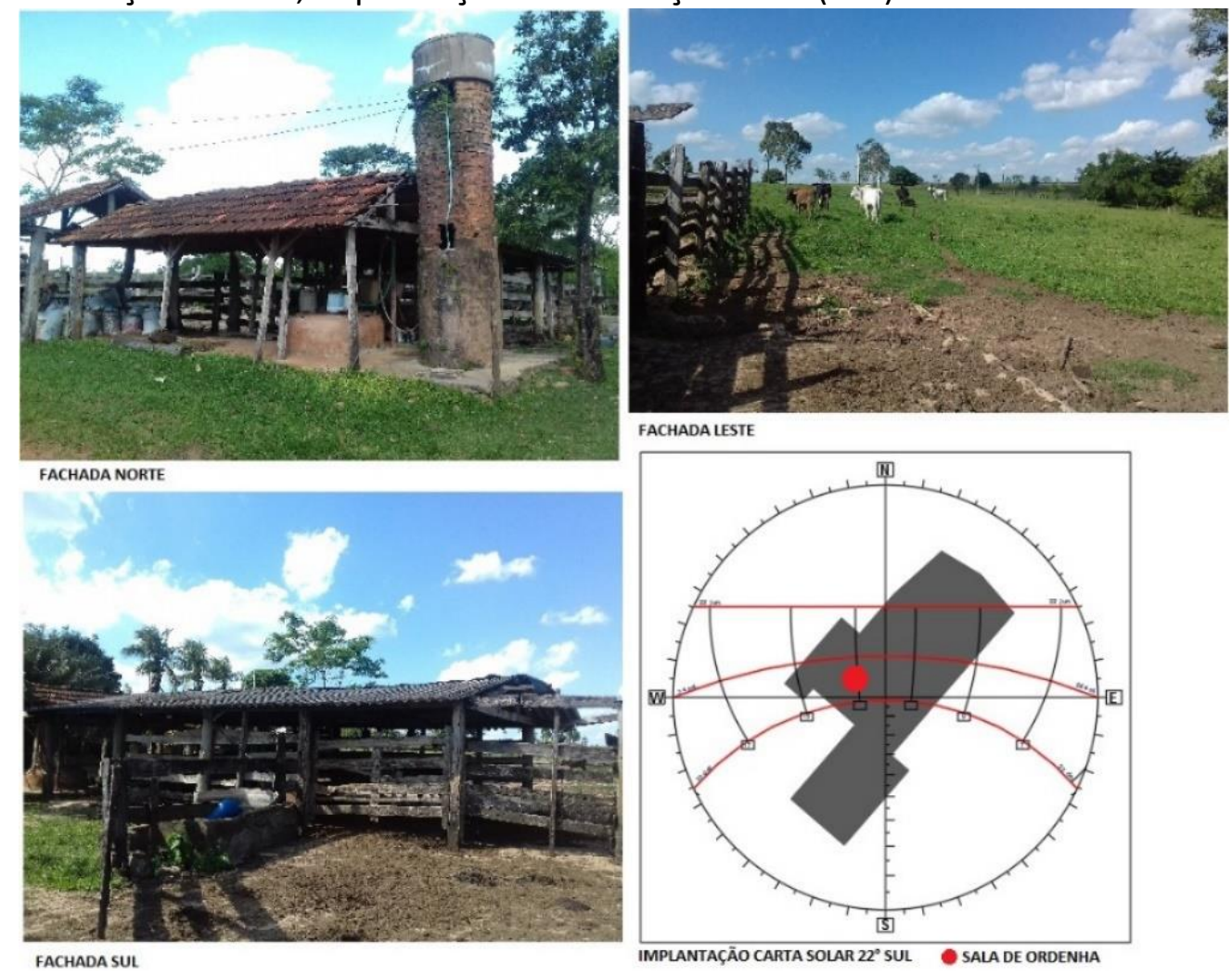

Fonte: Dados organizados pela autora, 2017

\section{ZONEAMENTO BIOCLIMÁTICO, NBR 15220-3 E AS CONSTRUÇÕES RURAIS DA BACIA LEITEIRA}

A NBR 15220-3 apresenta as diretrizes para elaboração de um projeto arquitetônico condizente com o meio ambiente em que será inserido, por meio de estratégias particulares para cada zona bioclimática do Brasil. De acordo com o Manual Para Aplicação de Regulamentos (RTQ-C e RAC-C) do ano de 2010, o zoneamento climático determina as diretrizes de um edifício para que este obtenha conforto térmico para seus ocupantes. Senso assim o zoneamento bioclimático é o cruzamento de informações como, zona de conforto térmico humano, dados de clima e estratégias de projeto arquitetônico e construção, que buscam o bem-estar humano.

O zoneamento bioclimático proposto pela NBR 15220-3 divide o país em 8 zonas climáticas a partir das temperaturas máximas, mínimas e umidades relativas do ar onde essas variáveis climáticas são mais homogêneas. O município de Anhumas está localizado na Zona bioclimática 06, com latitude de $-22,29$ e longitude de 51,39 e altitude de 422 metros.

De acordo com a NBR 15220 -3 entre as ações adotadas em projeto para garantir conforto térmico do ambiente com relação a ventilação natural as aberturas devem ser médias e sombreadas nas fachadas que passem mais tempo expostas a incidência solar. Os tamanhos das aberturas são definidos pela porcentagem da área de piso, ou seja, abertura média possui área de 15 a $25 \%$ da área do piso da edificação.

Com relação a vedação das paredes a NBR 15220 -3 determina para a zona bioclimática do município de Anhumas as seguintes características construtivas.

\section{Tabela 01: Propriedades das vedações externas para zona bioclimática $06^{1}$

$\begin{array}{llll}\text { Vedação Externa } & \text { Transmitância } & \text { Atraso Térmico - \$ } & \text { Fator Solar - FS。 }\end{array}$

\footnotetext{
${ }^{1}$ Os cálculos que definem esses valores em um projeto arquitetônico estão disponíveis na NBR 15220-2: Métodos de Cálculo de Transmitância Térmica, da capacidade térmica, do atraso térmico e do fator solar de elementos e componentes de edificações
} 


\begin{tabular}{llll} 
& Térmica $-U \mathrm{~W} / \mathrm{m}^{2} . \mathrm{K}$ & Horas & \\
\hline \multicolumn{1}{c}{ Parede Pesada } & $\mathrm{U} \leq 2,20$ & $\$ \leq 6,5$ & $\mathrm{FS} \circ \leq 3,5$ \\
\hline Cobertura leve isolada & $\mathrm{U} \leq 2,00$ & $\$ \leq 3,3$ & FS 56,5 \\
\hline Fonte: Adaptado de NBR 15220-3 (2003) & &
\end{tabular}

Com relação ao condicionamento térmico passivo, ou seja, aqueles que não fazem uso de energia elétrica ou combustíveis como, isolamentos térmicos em telhados, formas de aberturas, sombreamento do entorno, e outros. A NBR 15220, apresenta para o verão na zona bioclimática 6 a necessidade de resfriamento evaporativo e massa térmica para resfriamento, ventilação seletiva quando a temperatura no interior da edificação for superior a temperatura externa. No período de inverno a zona bioclimática 6 necessita de vedação pesada para que ocorra inércia térmica.

A propriedade A, com parede de alvenaria composta de tijolo de 6 furos circulares assentados na menor dimensão e espessura total de 15 centímetros apresenta de acordo com as normas da NBR 15220-3, fator de transmitância térmica entorno de $2,28 \mathrm{~W} / \mathrm{m}^{2}$, ou seja está acima do especificado na mesma norma para o ZB6 (zoneamento bioclimático 6) que deve ser abaixo de $2,20 \mathrm{~W} / \mathrm{m}^{2}$, porém o atraso térmico apresentado pela parede de alvenaria segundo a NBR 15220-3 é de 3,7 horas estando dentro do limite máximo exigido que é de 6,5 horas. A cobertura de zinco existente na propriedade $A$, possui transmitância térmica entorno de 2,84 $\mathrm{W} / \mathrm{m}^{2}$ estando também acima da norma e atraso térmico dentro do estabelecido pela norma, entorno de 1,06 horas.

A propriedade $B$ possui vedação lateral menor que a metade da área toda da construção, portanto foi considerado no estudo a transmitância térmica da cobertura, pois as paredes não interferem no aquecimento da edificação. A cobertura da edificação é de telha de fibrocimento e possui transmitância térmica entorno de $4,60 \mathrm{~W} / \mathrm{m}^{2}$ estando acima do estabelecido pela NBR 15220-3 e atraso térmico de 0,2 horas, estando dentro do estabelecido na norma.

\section{CONCLUSÃO}

Pode-se concluir que apesar de alguns indicies das construções rurais apresentem resultados dentro do estabelecido pela NBR 15220-3 elas não estão totalmente adequadas para a zona bioclimática 6 , pois os materiais construtivos conduzem calor do exterior para o interior da edificação calor acima do indicado na norma.

\section{REFERÊNCIAS BIBLIOGRÁFICAS}

BORGES, S.A.; MAIORKA, A.; FISHER DA SILVA, A.V. Fisiologia do estresse calórico e a utilização de eletrólitos em frangos de corte. Revista Ciência Rural, v.33, n.5, p.975-981, 2003 https://doi.org/10.1590/S0103-84782003000500028

BAÊTA, F.C.D; SOUZA, C.F.D. Ambiência em Edificações Rurais. Conforto Animal. Ed. UFV. 2o Edição, 269 p., ano 2012

CAMPOS, J. A. Bem-estar de suínos confinados associado a comportamento, sistema imunológico e desempenho. 200979 f. Tese (Doutorado) - Universidade Federal de Viçosa, Viçosa, MG, 2009

DIBIESO, E.P. Planejamento ambiental e gestão dos recursos hídricos: estudo aplicado à bacia hidrográfica do manancial do alto curso do rio santo anastácio - São Paulo. UNESP- Universidade Estadual Paulista Julio de Mesquita Filho, Presidente Prudente, 2012. 
ESMAY, M.L. Principles of animal enviroment. Environmental Engineering in Agriculture and Food Series. New York: The AVI Publishing Company, Inc., 325 p., 1969

FAWC, Farm Animal Welfare Council, 1992. Disponivel em http://webarchive.nationalarchives.gov.uk/20110909181140/http://www.fawc.org.uk/reports.ht m $\quad$ Acesso em: 22 junho de 2017

MOUNT, L.E. Adaptation of swine. In: Adaptation of domestic animals. Philadelphia: Lea \& Febiger, 1968. P 277-91

NBR 15220 Desempenho Térmico de Edificações Parte 3: Zoenamento Bioclimático Brasileiro e Diretrizes Construtivas para Habitações Unifamiliares de Interesse Social, 2003

TAKAHASHI, L.S.; BILLER, J.D.; TAKAHASHI, K.M. Bioclimatologia Zootécnica. 10 edição; Jaboticabal, 2009

TEIXEIRA, E. As três Medologias. 2ª ed. São Paulo, Vozes, 2000

VIANA, S.S.M. Conforto térmico nas Escolas Estaduais de Presidente Prudente/SPUNESP/Presidente Prudente, 2013 